\title{
Increasing dietary protein intake in community dwelling older adults: protocol for a randomised controlled trial and baseline data
}

\author{
E. van den Heuvel $^{1}$, J.L. Murphy ${ }^{2}$ and K.M. Appleton ${ }^{1}$ \\ ${ }^{1}$ Research Centre for Behaviour Change, Department of Psychology and \\ ${ }^{2}$ Faculty of Health and Social Sciences, Bournemouth University, Poole, BH12 5BB
}

Dietary protein has an important impact on health, physical functioning, and muscle mass, and it has been suggested that older adults need more dietary protein than younger adults ${ }^{(1)}$. Compared to other protein rich foods, eggs are easy to cook, of long shelf life, and low cost; so they may be of help in increasing protein intake in older adults. Reasons for eating or not eating eggs in adults aged 55 years and older were identified in a focus group study ${ }^{(2)}$ and then used to design a structured questionnaire which was sent out to a National sample ${ }^{(3)}$. Our questionnaire results showed that older adults who eat more eggs report that they think eggs taste good and add variety to the diet. Adding flavour and more variety may encourage intakes in those who consume fewer eggs.

A randomized controlled intervention study was designed to increase egg and protein intake, by providing recipes of protein-rich egg-based meals and herbs/spice packets, to encourage the addition of flavour and variety to the diet. Community dwelling adults aged 55 years and over were randomized to receive dietary information followed by either 6 recipes and relevant herbs/spices every fortnight for 3 months, or northing further. Dietary intake (Food Frequency Questionnaire ${ }^{(4)}$ ), body composition (Bioelectrical Impedance Analysis), handgrip strength, and physical performance (Short Physical Performance Battery (SPPB) ${ }^{(5)}$ ) were assessed at baseline, and will be assessed again after the 3-month intervention period and at a 6-month follow up. The study is registered at ClinicalTrials.gov (NCT02777918). All participants have so far completed baseline sessions.

A total of 100 participants are taking part - 54 females and 46 males; mean age at baseline was $70 \pm 7$ years, range 55-97 years. Egg intake was $22 \pm 16$ eggs per month, which is higher than the National Diet and Nutrition Survey data indicating that British older adults (65yrs+) consume $33 \mathrm{~g}$ of eggs and egg dishes per month (equivalent to up to 16-17 eggs). Reported protein intake was $1.24 \pm 0.42 \mathrm{~g} / \mathrm{kg} /$ day. In this sample, $10 \%$ did not meet the Reference Nutrient Intake for all adults of $0.75 \mathrm{~g} / \mathrm{kg} / \mathrm{day}$, and $50 \%$ did not meet the $1.2 \mathrm{~g} / \mathrm{kg} /$ day which has been suggested as the protein requirement for older adults ${ }^{(1)}$. Mean BMI was $27 \pm 4 \mathrm{~kg} / \mathrm{m}^{2}$; lean mass (LM) percentage was $61 \pm 6 \%$ for females, and $74 \pm 5 \%$ for males; handgrip strength was $25 \pm 4 \mathrm{~kg}$ for females, and $40 \pm 9 \mathrm{~kg}$ for males; and SPPB score (0-12) was $9 \pm 2$. In our sample, $11 \%$ of the females and $9 \%$ of the males could be classified as sarcopenic based on handgrip strength ${ }^{(6)}$, which is within the estimated range of sarcopenia in community dwelling populations $(1-29 \% \text { prevalence })^{(7)}$.

Providing recipes could be a straightforward to implement strategy to encourage older adults to consume more eggs and more protein, which could support good health.

1. Bauer J, Biolo G, Cederholm T et al. (2013) J Am Med Dir Assoc 14, 542-559.

2. van den Heuvel E, Murphy JL, Appleton KM (2015) Proc Nutr Soc 74, 314.

3. van den Heuvel E, Murphy JL, Appleton KM (2016) Proc Nutr Soc 75, 196.

4. Clark H (2017) Scottish collaborative group food frequency questionnaire service. [accessed March 2017]. Available from: http://www.foodfrequency. org/.

5. Guralnik JM, Simonsick EM, Ferrucci L et al. (1994) J Gerontol 49, M85-M94.

6. Cruz-Jentoft AJ, Baeyens JP, Bauer JM et al. (2010) Age Ageing 39, 412-423.

7. Cruz-Jentoft AJ, Landi F, Schneider SM et al. (2014) Age Ageing 43, 748-759. 